\title{
THE INDIVIDUAL TOLERANCE CONCEPT IS NOT THE SOLE EXPLANATION FOR THE PROBIT DOSE-EFFECT MODEL
}

\author{
Michael C. Newman*† and John T. McCloskey \\ $\dagger$ College of William and Mary, Virginia Institute of Marine Science, Gloucester Point, Virginia 23062-1346, USA \\ $\ddagger$ U.S. Fish and Wildlife Service, 6669 Short Lane, P.O. Box 99, Gloucester, Virginia 23061
}

(Received 12 February 1999; Accepted 14 June 1999)

\begin{abstract}
Predominant methods for analyzing dose- or concentration-effect data (i.e., probit analysis) are based on the concept of individual tolerance or individual effective dose (IED, the smallest characteristic dose needed to kill an individual). An alternative explanation (stochasticity hypothesis) is that individuals do not have unique tolerances: death results from stochastic processes occurring similarly in all individuals. These opposing hypotheses were tested with two types of experiments. First, time to stupefaction (TTS) was measured for zebra fish (Brachydanio rerio) exposed to benzocaine. The same 40 fish were exposed during five trials to test if the same order for TTS was maintained among trials. The IED hypothesis was supported with a minor stochastic component being present. Second, eastern mosquitofish (Gambusia holbrooki) were exposed to sublethal or lethal $\mathrm{NaCl}$ concentrations until a large portion of the lethally exposed fish died. After sufficient time for recovery, fish sublethally exposed and fish surviving lethal exposure were exposed simultaneously to lethal $\mathrm{NaCl}$ concentrations. No statistically significant effect was found of previous exposure on survival time but a large stochastic component to the survival dynamics was obvious. Repetition of this second type of test with pentachlorophenol also provided no support for the IED hypothesis. We conclude that neither hypothesis alone was the sole or dominant explanation for the lognormal (probit) model. Determination of the correct explanation (IED or stochastic) or the relative contributions of each is crucial to predicting consequences to populations after repeated or chronic exposures to any particular toxicant.
\end{abstract}

Keywords-Toxicity Dose-effect model Probit Lognormal distribution Tolerance

\section{INTRODUCTION}

A lognormal model is the basis for probit analysis, the most frequently applied method for fitting dose- or concentrationeffect data. An explanation for this model was provided by Gaddum (credited by Bliss and Cattell [1]) soon after probit methods were introduced into toxicology. Every individual has an innate quality called an individual tolerance or individual effective dose (IED) [2-4], and dies only if it receives a dose equal to or greater than its IED. The distribution of IED values among individuals in populations was best described with a lognormal model. Examples of conformity to the lognormal model were invoked to support the IED concept, with most focus on countering early supporters of the logistic (logit) model who criticized the lognormal model by attacking the IED concept. The most frequently presented, early example was a bioassay in which cats were slowly infused with increasing amounts of digitalis until their hearts stopped beating. Although the distribution of lethal doses was lognormal in most such examples and supporters of the logistic model were effectively countered, it remained impossible to test the IED concept because individuals could not be rechallenged.

Despite its universal acceptance today, the IED concept may not be a complete explanation for all applications of the lognormal model. An early rechallenge experiment did not support the IED concept [5]. The wide use of the lognormal model for diverse lethal and sublethal effects based on this one concept seems dubious because these effects have widely differing causal structures. The application of the lognormal model to

* To whom correspondence may be addressed (newman@ vims.edu). Contribution 2222 of the College of William and Mary's Virginia Institute of Marine Science and School of Marine Science. both clonal (e.g., Daphnia magna, Vibrio fischeri, and Caenorhabditis elegans cultures) and nonclonal (inbred lines and wild-caught) collections of individuals imposes one explanation onto extremely different groups of individuals. The relative contributions of genetic, developmental, and environmental variation on tolerance would be very different among these categories of test species, yet the same explanation would be provided for the use of probit methods. It would be remarkably fortuitous if, for such diverse groupings, all sublethal and lethal effects emerging from diverse mechanisms were dominated by some innate tolerance factor that was lognormally distributed among individuals. This IED concept is also inconsistent with the conceptual foundations of other models of effect, that is, many models for survival time and carcinogenesis.

Another plausible explanation exists for the lognormal model. Identical, but stochastic, processes occur within all individuals with the chance of death being essentially the same for all individuals receiving a dose. The multistage model for carcinogenesis is one widely applied class of dose-effect models with such stochastic underpinnings. The probability of an individual dying increases with increasing dose. A suitable model describing the stochastic variation in mortality among individuals is the cumulative lognormal distribution. The distinction between the two hypotheses is that the variation in mortality is (IED hypothesis) or is not (stochasticity hypothesis) due primarily to a unique quality of individuals.

The lack of rigorous testing of the underlying mechanism for the lognormal model is surprising because the dose-effect relationship is one of the most fundamental in toxicology [6,7]. Part of the explanation is the preoccupation with deciding whether the lognormal or log-logistic model is the best for 
fitting data. Regardless, the favored status of the IED hypothesis as an explanation is a consequence of its repeated use during the last 60 years, not its survival of rigorous testing. The IED hypothesis remains the sole explanation put forward in technical books $[7,8]$, textbooks $[9,10]$, and statistical manuals [11].

The importance of determining the underlying mechanism for the lognormal model is easily illustrated. Assume that a population of individuals exists below a source that releases a toxicant at one LC50 for 96 -h periods. Assume also that several releases occur with sufficient time for recovery between them. According to the IED hypothesis, 50\% of individuals would be killed during the first release but no, or very minimal, mortality would occur during subsequent exposures: all survivors of the first exposure would have individual tolerance values greater than the LC50. In contrast, under the stochasticity hypothesis, $50 \%$ of individuals alive at the beginning of any exposure would die by the end of that exposure, for example, a sequence of $100 \% \rightarrow 50 \% \rightarrow 25 \% \rightarrow 12.5 \%$ $\rightarrow 6.25 \% \rightarrow$ and so on surviving of the original number of individuals.

Two types of experiments were performed to test which hypothesis provided the best explanation for the lognormal model. Both take advantage of time to response at a fixed exposure concentration as a measure of tolerance instead of the conventional effective dose or concentration metric for a fixed exposure duration [12]. The first experiments involved measurement of time to stupefaction (TTS) (stage 4 of anesthesia [13]) for 40 zebra fish (Brachydanio rerio) exposed repeatedly to benzocaine. The IED hypothesis predicts that the fish would maintain the same relative tolerances during repeated exposures. The stochasticity hypothesis predicts no concordance in TTS among challenges. The second type of experiment involved simultaneous exposure of subsamples of eastern mosquitofish (Gambusia holbrooki) to either sublethal or lethal concentrations of toxicant for sufficient duration to kill approximately $50 \%$ of the lethally exposed individuals. After giving both groups sufficient time to recover, the sublethally exposed fish and survivors of the lethal exposure were lethally challenged. Cumulative mortality was measured through time for all exposures. The IED hypothesis predicts high mortality for the sublethally challenged individuals during this second exposure but very minimal mortality for the survivors of the initial lethal exposure. The stochasticity hypothesis predicts identical mortality curves for the two groups regardless of their exposure histories. This second type of experiment was done with two toxicants with different modes of action, $\mathrm{NaCl}$ and pentachlorophenol (PCP).

\section{MATERIALS AND METHODS}

\section{Benzocaine exposure and TTS}

Fish source and maintenance. Forty zebra fish were purchased from a local supplier and maintained in a 38-L tank of reconstituted hard water $\left(192.0 \mathrm{mg} / \mathrm{L} \mathrm{NaHCO}{ }_{3}, 120.0 \mathrm{mg} / \mathrm{L}\right.$ $\mathrm{CaSO}_{4} \cdot 2 \mathrm{H}_{2} \mathrm{O}, 120.0 \mathrm{mg} / \mathrm{L} \mathrm{MgSO}_{4}$, and $8.0 \mathrm{mg} / \mathrm{L} \mathrm{KCl}$ added to deionized water [14]) at $25^{\circ} \mathrm{C}$. Fish were provided a maintenance diet of Tetramin ${ }^{\circledR}$ (TetraWerke, Melle, Germany) tropical fish food.

Sequential exposure to benzocaine. Fish were weighed (mean \pm standard deviation: $0.26 \pm 0.01 \mathrm{~g}$ wet weight, $n=$ 40) and placed in numbered 236-ml polypropylene containers that had been perforated. These numbered containers with fish were placed into a $33-\mathrm{L}$ plexiglass chamber of reconstituted hard water maintained at $25^{\circ} \mathrm{C}$ for $10 \mathrm{~d}$ before the initial exposure. A nominally $50-\mathrm{mg} / \mathrm{L}$ benzocaine solution was prepared in $1 \mathrm{~L}$ of reconstituted hard water and stirred for a minimum of $8 \mathrm{~h}$ to ensure complete dissolution. For the exposure, individual containers with fish were randomly placed into a glass tank containing $1 \mathrm{~L}$ of the benzocaine solution $\left(25^{\circ} \mathrm{C}\right)$ and TTS was noted for each fish. A total of 40 fish were individually exposed. This was repeated five times with $7 \mathrm{~d}$ to recover between trials so that five TTSs were generated for each fish. Fish were fed twice between trials. Minimal weight change of fish fed the maintenance diet was evidenced by the final weights (mean \pm standard deviation: $0.23 \pm 0.02$ g wet weight, $n=40$ ), which were slightly lower than initial weights.

Benzocaine measurement. Benzocaine concentrations were measured four times during each trial using a Beckman DU70 spectrophotometer (Beckman Instruments, Fullerton, CA, USA) to ensure that benzocaine concentrations had not changed. Absorbance at $286 \mathrm{~nm}$ was a linear function of benzocaine concentration in the range of 0 to $10 \mathrm{mg} / \mathrm{L}$ with all standard curves having $r^{2}$ values greater than 0.99 . Initial monitoring of artificial hard water absorbance in containers containing fish for up to $5 \mathrm{~min}$ indicated that no measurable amounts of substances absorbing at $286 \mathrm{~nm}$ were released from fish during the trials.

\section{Mosquitofish mortality: $\mathrm{NaCl}$ and PCP}

Fish collection and maintenance. For the $\mathrm{NaCl}$ experiment, eastern mosquitofish were taken from a population (Risher Pond, Aiken, SC, USA) used in past toxicologic studies $[12,15,16]$. Fish were collected by dip net and seine, and placed in a 520-L Living Streams ${ }^{\text {(ix) }}$ tank (Frigid Units, Toledo, $\mathrm{OH}$, USA) containing reconstituted soft water $\left(48.0 \mathrm{mg} / \mathrm{L} \mathrm{NaHCO}_{3}\right.$, $30.0 \mathrm{mg} / \mathrm{L} \mathrm{CaSO}_{4} \cdot 2 \mathrm{H}_{2} \mathrm{O}, 30.0 \mathrm{mg} / \mathrm{L} \mathrm{MgSO}_{4}$, and $2.0 \mathrm{mg} / \mathrm{L} \mathrm{KCl}$ added to deionized water [14]) and maintained at $21^{\circ} \mathrm{C}$. Within $24 \mathrm{~h}$ of capture, fish were treated with Maracyn-Two ${ }^{\mathbb{N a x}}$ (Mardel Laboratories, Glendale Heights, IL, USA) to control bacterial infections. Fish were treated daily for $2 \mathrm{~h}$ with a combination of malachite green $(0.25 \mathrm{mg} / \mathrm{L})$ and formalin $(25 \mathrm{mg} / \mathrm{L})$ to control disease during the first 2 weeks of captivity.

Females of similar size were removed and placed in a 720 L Living Streams tank (Model LS-900, Frigid Units) containing reconstituted soft water $\left(21^{\circ} \mathrm{C}\right)$. Malachite green and formalin treatments were continued three times per week and the tank was equipped with a $15-\mathrm{W}$ ultraviolet sterilizer (Aquanetics Systems, San Diego, CA, USA). Treatment with malachite green and formalin was discontinued 1 week before the experiments. Daily feedings of Tetramin tropical fish food were stopped $24 \mathrm{~h}$ before exposures.

Sodium chloride experiment. Initial exposure. After a 2week acclimation to the test temperature, 520 female mosquitofish were randomly assigned to two 171-L glass aquaria (160 fish to the sublethal-exposure tank and 360 fish to the lethal-exposure tank) receiving a constant flow of reconstituted soft water $\left(0.4 \mathrm{~L} / \mathrm{min}, 21^{\circ} \mathrm{C}\right)$. Fish were acclimated to the tanks for $24 \mathrm{~h}$ before initiation of exposure. Reconstituted soft water was spiked with nominal concentrations of 5,000 (sublethalexposure tank) and 12,000 (lethal-exposure tank) mg/L of reagent-grade $\mathrm{NaCl}$ (Fisher Scientific, Pittsburgh, PA, USA). These concentrations were chosen based on previous studies using mosquitofish and $\mathrm{NaCl}[14,15]$. Tanks were checked daily for mortality and fish wet weight was measured at death.

Once mortality in the lethal tank reached approximately 
Table 1. Water quality measured during initial and second exposures in the $\mathrm{NaCl}$ and pentachlorophenol (PCP) experiments. All values are mean \pm standard deviation, except for $\mathrm{pH}$, which is the median (range)

\begin{tabular}{lcc}
\hline & NaCl experiment & PCP experiment \\
\hline Initial exposure & & $19.3 \pm 0.1(n=2)$ \\
Temperature $\left({ }^{\circ} \mathrm{C}\right)$ & $20.4 \pm 0.5(n=10)$ & $7.0 \pm 0.2(n=2)$ \\
Dissolved oxygen $(\mathrm{mg} / \mathrm{L})$ & $8.2 \pm 0.4(n=10)$ & $6.9(6.7-7.0)(n=2)$ \\
$\mathrm{pH}$ & $7.5(7.4-7.6)(n=10)$ & $354 \pm 25(n=2)$ \\
Water flow $(\mathrm{ml} / \mathrm{min})$ & $342 \pm 30(n=10)$ & $18.3 \pm 1.1(n=16)$ \\
Second exposure & & $7.2 \pm 0.9(n=16)$ \\
Temperature $\left({ }^{\circ} \mathrm{C}\right)$ & $20.4 \pm 0.8(n=60)$ & $7.5(6.9-7.7)(n=16)$ \\
Dissolved oxygen $(\mathrm{mg} / \mathrm{L})$ & $7.6 \pm 0.8(n=60)$ & $90.8 \pm 26.0(n=16)$ \\
pH & $7.3(6.6-7.7)(n=60)$ & $91.3 \pm 24.7(n=60)$ \\
Water flow $(\mathrm{ml} / \mathrm{min})$ & & \\
\hline
\end{tabular}

$12 \%$ (144 h; 43 of 360 dead), reconstituted soft water without $\mathrm{NaCl}$ was delivered to both tanks to bring water back to preexposure conditions. Exposure was terminated at this point because fish continue to die for several days after ending salt exposure. During the exposure and the period immediately after exposure, a total of $56 \%$ of the lethally exposed fish and none of the sublethally exposed fish died. Wet weight of fish dying during this treatment was $0.39 \pm 0.17 \mathrm{~g}(n=202$ dying of 360 lethally exposed). Wet weights for the 43 fish dying during and 159 dying after exposure were $0.33 \pm 0.15 \mathrm{~g}$ and $0.41 \pm 0.18 \mathrm{~g}$, respectively. Surviving fish from each treatment were then moved back into separate compartments of the 720$\mathrm{L}$ tank. Fish were held for a minimum of 4 weeks from the end of the first exposure to the beginning the second exposure.

Second exposure. Fish surviving the initial exposure from each group (sublethal and lethal exposure) were randomly assigned to each of four $38-\mathrm{L}$ tanks receiving a continuous flow $(0.1 \mathrm{~L} / \mathrm{min})$ of reconstituted soft water $\left(21^{\circ} \mathrm{C}\right)$. Each test tank was divided in half using an open-mesh partition to keep fish from the two groups separated. Fish were acclimated to the test tanks for $24 \mathrm{~h}$ before initiation of exposure. Reconstituted soft water was spiked with nominal concentrations of 0 and $12,000 \mathrm{mg} / \mathrm{L}$ of reagent-grade $\mathrm{NaCl}$ and delivered $(0.1 \mathrm{~L} / \mathrm{min})$ to the two pairs of tanks. Mean \pm standard deviation of wet weights for fish of the sublethal- and lethal-exposure groups were $0.55 \pm 0.24 \mathrm{~g}(n=128)$ and $0.50 \pm 0.25 \mathrm{~g}(n=123)$, respectively. Tanks were checked for mortality every 4 to $8 \mathrm{~h}$ for a total of $387 \mathrm{~h}$ and wet weight for each fish was measured at death.

Pentachlorophenol experiment. Initial exposure. Initial $\mathrm{PCP}$ exposure design was the same as that for $\mathrm{NaCl}$ exposures. Female mosquitofish were randomly assigned to two $171-\mathrm{L}$ aquaria (150 fish to the sublethal-exposure tank and 300 fish to the lethal-exposure tank) with a flow rate of $0.4 \mathrm{~L} / \mathrm{min}$ and water temperature of $21^{\circ} \mathrm{C}$. Fish were acclimated to the test tanks for $24 \mathrm{~h}$ before initiation of the PCP exposure. Reconstituted soft water was spiked with nominal concentrations of PCP (sodium salt; Aldrich Chemical, Milwaukee, WI, USA) of $200 \mathrm{~g} / \mathrm{L}$ (sublethal-exposure tank) or $500 \mathrm{~g} / \mathrm{L}$ (lethal-exposure tank). Tanks were checked every few hours for mortality and fish wet weight was determined at death.

Once mortality in the lethal-exposure tank approached $30 \%$ ( $24 \mathrm{~h})$, reconstituted soft water without PCP was delivered into both tanks to bring water back to preexposure conditions. At that time, 81 fish $(27 \%$, mean \pm standard deviation of wet weight $=0.40 \pm 0.22 \mathrm{~g}$ ) had died. The postexposure mortality for PCP was much lower proportionally and more immediate than that for $\mathrm{NaCl}$. All postexposure mortality occurred within
$8 \mathrm{~h}$ of cessation of PCP exposure, whereas significant postexposure mortality for $\mathrm{NaCl}$ continued for 3 to 4 weeks. After a 2-d postexposure period, mortalities for lethally and sublethally exposed fish were 42 and $0 \%$, respectively. The wet weights of the 44 fish dying after ending exposure were 0.475 $\pm 0.250 \mathrm{~g}$ (mean \pm standard deviation). Surviving fish from each treatment were moved into separate compartments of the 720-L tank and held for 4 weeks before initiating the second PCP exposure. Based on PCP uptake and elimination studies with the similar-sized killifish (Oryzias latipes), 4 weeks was sufficient for the depuration of most of the PCP and conjugated PCP (PCP glucuronide and PCP sulfate) [17]. Using the most conservative elimination rate constants for killifish held at similar temperatures, only $0.1 \%$ of the accumulated PCP (including conjugated PCP) would remain in the fish after 4 weeks of elimination.

Second exposure. Survivors of the initial exposure from each group (sublethal and lethal exposure) were randomly assigned to four 38-L tanks. The two control tanks each received 30 fish (15 on each side) and the two exposure tanks (tanks $\mathrm{A}$ and $\mathrm{B}$ ) received 110 or 111 fish each. Wet weights of fish (mean \pm standard deviation $[n]$ ) for exposure tank A (sublethal exposure), tank A (lethal exposure), tank B (sublethal exposure), and tank B (lethal exposure) were $0.42 \pm 0.24 \mathrm{~g}$ (46), $0.53 \pm 0.24 \mathrm{~g}(64), 0.49 \pm 0.26 \mathrm{~g}$ (48), and $0.57 \pm 0.30 \mathrm{~g}$ (63), respectively. The tanks received $0.1 \mathrm{~L} / \mathrm{min}$ of reconstituted soft water maintained at $21^{\circ} \mathrm{C}$. Each test tank was divided in half using an open-mesh partition to keep fish from the groups separated. Fish were acclimated to the test tanks for $24 \mathrm{~h}$ before exposure. Reconstituted soft water was spiked with nominal concentrations of PCP at 0 and $475 \mu \mathrm{g} / \mathrm{L}$, and delivered to the two pairs of tanks at a rate of $0.1 \mathrm{~L} / \mathrm{min}$. Mortality in tanks was checked every 2 to $8 \mathrm{~h}$ for $104 \mathrm{~h}$.

Toxicant measurement and water quality. For the initial exposures, temperature, dissolved oxygen, $\mathrm{pH}$, and conductivity were measured daily using a Hydrolab ${ }^{\mathbb{( N D}}$ multiprobe unit (Hydrolab, Austin, TX, USA) with the exception that $\mathrm{pH}$ was measured using an Orion ionalyzer (Orion, Beverly, MA, USA) during the $\mathrm{NaCl}$ experiment (Table 1).

For the $\mathrm{NaCl}$ experiment, samples taken daily were refrigerated and $\mathrm{Na}$ concentrations determined using a Perkin Elmer Model 5100 PC atomic absorption spectrophotometer (Perkin Elmer, Norwalk, CT, USA). Sodium chloride concentrations were calculated from $\mathrm{Cl}$ concentrations. Past $\mathrm{NaCl}$ toxicity testing $[12,15]$ indicated that measurement of $\mathrm{Na}$ was adequate to accurately define $\mathrm{NaCl}$ concentrations.

Samples for PCP analysis were collected daily in polyethylene bottles and analyzed using the method of Carr et al. [18]. 


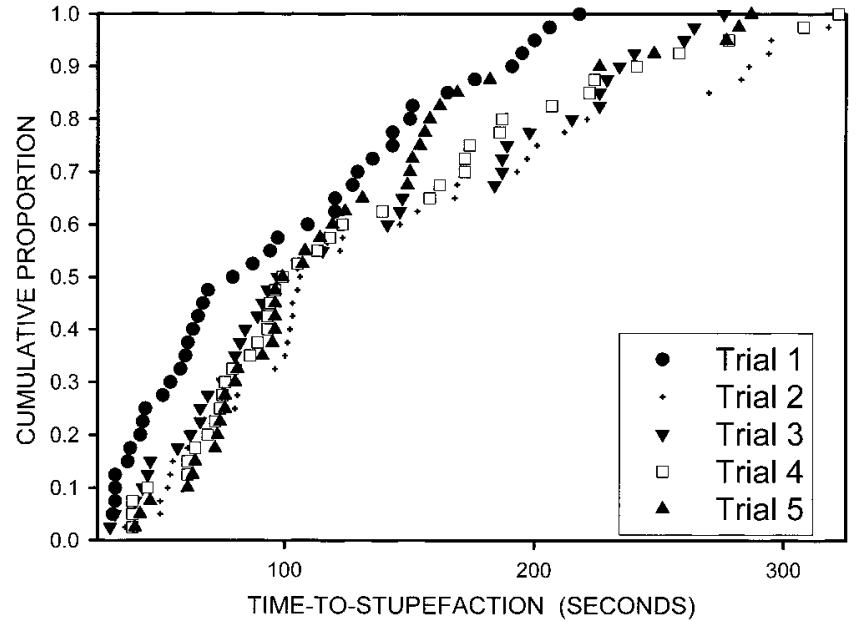

Fig. 1. Time to stupefaction (s) for zebra fish exposed repeatedly to benzocaine.

Water samples were acidified with concentrated $\mathrm{HCl}(1 \mathrm{ml}$ of $\mathrm{HCl}$ per $100 \mathrm{ml}$ sample) and $10 \mathrm{ml}$ of chloroform was then added to each. The samples were shaken vigorously for $60 \mathrm{~s}$ and $5 \mathrm{ml}$ of the chloroform extract was collected from each. Next, $2 \mathrm{ml}$ of $200 \mathrm{mM} \mathrm{NaOH}$ was added to each chloroform extract, which were mixed vigorously for another $30 \mathrm{~s}$. The absorbance of the aqueous fractions at $\lambda=320 \mathrm{~nm}$ was measured using a Beckman Model DU-70 spectrophotometer.

\section{RESULTS}

\section{Benzocaine exposure and TTS}

Benzocaine concentrations measured during trials 1 to 5 (mean \pm standard deviation, $n=4$ ) were $52.5 \pm 2.5 \mathrm{mg} / \mathrm{L}$, $52.6 \pm 1.7 \mathrm{mg} / \mathrm{L}, 51.3 \pm 0.7 \mathrm{mg} / \mathrm{L}, 50.5 \pm 0.1 \mathrm{mg} / \mathrm{L}$, and $49.9 \pm 0.2 \mathrm{mg} / \mathrm{L}$, respectively. Overall analysis precision and accuracy were $0.9 \%$ relative standard deviation and $99.6 \%$ recovery, respectively.

Data were analyzed with a mixed, general linear model (Proc Mixed of SAS [19]), with the response variable being natural logarithm of TTS. Trial was fixed in the blocked design because of small differences in concentration among trials. Fish identity was included as a random effect because inferences were to be made about zebra fish exposed to benzocaine, not about these 40 zebra fish. Adjustment for the natural logarithm of fish weight (fixed) was done because ample precedence exists for this correction [15], the $F$ statistic for ln of wet weight indicated a highly significant $(p=0.002)$ effect in the model, and exclusion of this adjustment in the model decreased the Akaike's information criterion from -97 to -102 . Akaike's information criterion indicates the best of candidate models that differ in complexity.

No consistent temporal trends in tolerances were apparent among trials (Fig. 1), suggesting no obvious induction of detoxification mechanisms after repeated exposures or cumulative damage. A suggestion existed that fish might have been more sensitive in trial 1 than in the other trials. However, that trial had one of the highest mean PCP concentrations, which could explain the slight difference. Statistical conclusions did not change if data from this trial were omitted from analyses. Beyond that just mentioned for trial 1 , no obvious trends were associated with the differences in benzocaine concentrations among trials. Regardless, trial was a fixed variable in the model and had a significant effect $(p<0.001)$ on $\ln$ of TTS. Natural logarithm of fish wet weight (fixed) was also significant ( $p=$ 0.002 ) and, most importantly, the effect of fish identity was statistically significant ( $p=0.001)$. The variance component associated with fish identity (variance estimate: $0.220 \pm 0.050$ ) was approximately three times higher than the residual variance component (variance estimate: $0.084 \pm 0.010$ ), indicating the importance of fish identity on determining response time.

\section{Mosquitofish mortality: $\mathrm{NaCl}$ and $\mathrm{PCP}$}

Sodium chloride experiment. Sodium and calculated $\mathrm{NaCl}$ concentrations for the initial exposures were the following (mean \pm standard deviation, $n=5$ ): sublethal exposure, 2,175 $\pm 67 \mathrm{mg} / \mathrm{L} \mathrm{Na}$ or $5,528 \pm 169 \mathrm{mg} / \mathrm{L} \mathrm{NaCl}$; lethal exposure, $5,125 \pm 275 \mathrm{mg} / \mathrm{L} \mathrm{Na}$ or $13,025 \pm 699 \mathrm{mg} / \mathrm{L} \mathrm{NaCl}$. Those measured for the second exposure were the following $(n=$ 30): sublethal exposure, $15.87 \pm 1.08 \mathrm{mg} / \mathrm{L} \mathrm{Na}$ or $40.34 \pm$ $2.75 \mathrm{mg} / \mathrm{L} \mathrm{NaCl}$; lethal exposure, 5,457 $\pm 418 \mathrm{mg} / \mathrm{L} \mathrm{Na}$ or $13,869 \pm 1,061 \mathrm{mg} / \mathrm{L} \mathrm{NaCl}$. Overall $\mathrm{NaCl}$ precision and accuracy were $8.3 \%$ relative standard deviation and $104 \%$ recovery, respectively.

Results for fish from the two tanks for each treatment were pooled because preliminary analysis (nonparametric survival analysis implemented with SAS Proc Lifetest [11]) showed no significant effect of tank on time to death (TTD) $(\alpha=0.05)$. Then data were fit to an accelerated failure time model (SAS Proc Lifereg, distribution $=$ Weibull) with preexposure treatment (sublethal- or lethal-exposure treatment) as a categorical variable and $\ln$ of fish wet weight as a continuous variable. These models predict TTDs as a function of covariate values that differ among individuals, for example, wet weight and exposure concentration. The accelerated failure time model was the following:

$$
\mathrm{TTD}=e^{b_{1}} e^{b_{2} \text { (treatment) }} e^{b_{3} \text { (ln weight) }} e^{W \sigma}
$$

with treatment $=0$ for the sublethal-exposure group or 1 for the lethal-exposure group, ln weight $=$ natural logarithm of fish wet weight $(\mathrm{g})$, and $W=-0.36651$ for prediction of the median TTD assuming a Weibull distribution. The estimated parameters were $b_{1}$, intercept; $b_{2}$, coefficient for the treatment effect; $b_{3}$, coefficient for the effect of $\ln$ weight; and $\sigma$ (scale parameter). The Weibull model was selected after initial assessment of the Weibull, log-logistic, and lognormal models showed minimal difference among candidate models based on their log-likelihood statistics.

No control deaths occurred by the end of the lethal exposure (387 h) but high mortality occurred for lethally challenged fish in both treatments and tanks (Fig. 2). Cursory inspection of cumulative mortality for the lethally challenged fish suggested that the fish that had survived a previous lethal challenge might have been slightly more tolerant than those previously exposed to sublethal concentrations; however, statistical analyses (Table 2) indicated no significant difference. Also, within the size range used in the test, fish size did not have a significant influence on TTD.

Pentachlorophenol experiment. Pentachlorophenol concentrations during the initial exposure were the following (mean \pm standard deviation, $n=3$ ): sublethal exposure, $199 \pm 10$ $\mu \mathrm{g} / \mathrm{L}$; lethal exposure, $561 \pm 95 \mu \mathrm{g} / \mathrm{L}$. Those measured during the second exposure were the following $(n=3)$ : control exposure, less than the detection limit of $50 \mu \mathrm{g} / \mathrm{L}$; lethal exposure, $388 \pm 27 \mu \mathrm{g} / \mathrm{L}$. Overall PCP analysis precision and accuracy were $5.3 \%$ relative standard deviation and $94 \%$ recovery, respectively. 


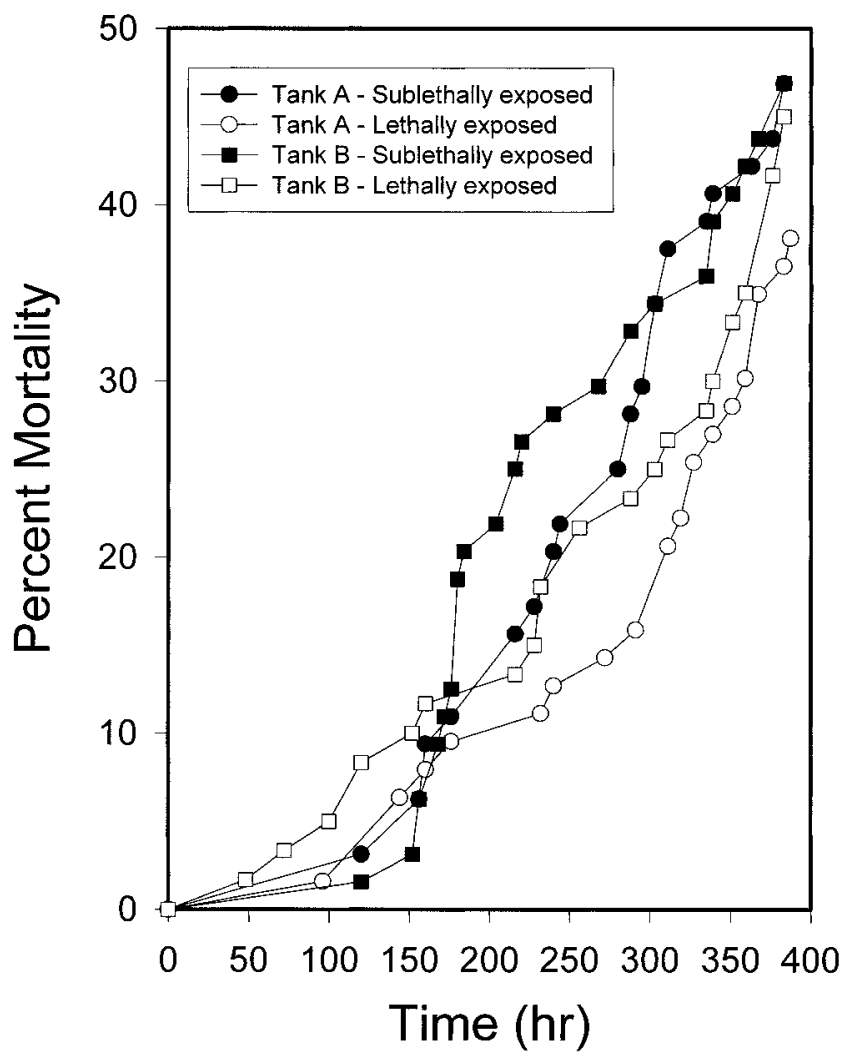

Fig. 2. Cumulative mortality of mosquitofish exposed to lethal concentrations of $\mathrm{NaCl}$. Mortality is shown for mosquitofish preexposed to sublethal concentrations of $\mathrm{NaCl}$ (sublethally exposed) or mosquitofish surviving a preexposure to lethal concentrations of $\mathrm{NaCl}$ (lethally exposed). Fish from both treatments were split between two tanks (tanks A and B).

Unlike the $\mathrm{NaCl}$ data, data for the two tanks for each treatment were not pooled because preliminary analysis (SAS Proc Lifetest [11]) found a significant $(\alpha=0.05)$ effect of tank on TTD (Fig. 3). Likely, this was a result of the slightly different rates of unspiked water displacement at the beginning of exposures which produced higher PCP concentrations on exposure day 1 in tank B $(386 \mu \mathrm{g} / \mathrm{L})$ than in tank A $(354 \mu \mathrm{g} /$ L). Analyzing mortality in each tank separately, a log-logistic model was found to be the best accelerated failure time model based on the log likelihood statistics for the log-logistic, Weibull, and lognormal models. The resulting models (Table 3) for each tank had the same form as that shown above for $\mathrm{NaCl}$ toxicity except $W=0$ for predicting the median TTD with the log-logistic model.

\section{DISCUSSION}

\section{Benzocaine exposure and TTS}

Anesthetic effect (time to reach phase 4) was influenced by fish size, with smaller fish being more sensitive than large fish.

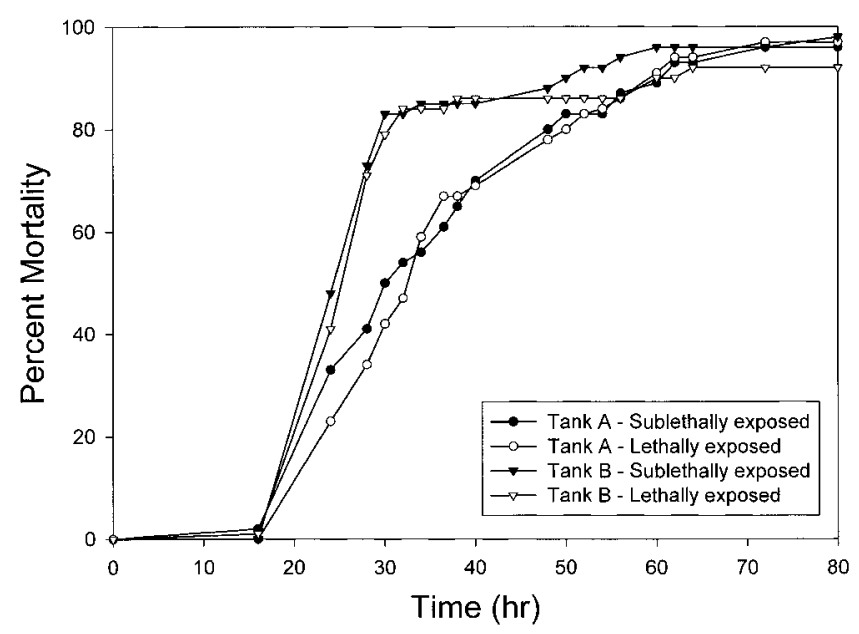

Fig. 3. Cumulative mortality of mosquitofish exposed to lethal concentrations of pentachlorophenol (PCP). Mortality is shown for mosquitofish preexposed to sublethal concentrations of PCP (sublethally exposed) or mosquitofish surviving a preexposure to lethal concentrations of PCP (lethally exposed). Fish from both treatments were split between two tanks (tanks A and B).

Beyond this effect of fish size, another quality of individuals significantly influenced sensitivity. This finding supports the IED concept that tolerance was an innate quality of individuals; however, a minor portion of the variation in response (approx. $28 \%$ ) remained in the error term.

\section{Mosquitofish mortality: $\mathrm{NaCl}$ and PCP}

The $\mathrm{NaCl}$ experiment provided no substantive evidence for the IED concept that tolerance is an innate quality of individuals. Plots, but not statistical tests, suggested a small difference in sensitivity between groups of mosquitofish that had or had not been previously challenged lethally. This small difference could be explained by the fish with lowest IED values being culled out during the first lethal exposure. Survivors (those with the higher IED values) would be less sensitive during a second lethal challenge than mosquitofish that had been sublethally challenged (those having the same distribution of IED values as the original population). However, because the first $(13,025 \mathrm{mg} / \mathrm{L} \mathrm{NaCl})$ and second $(13,869 \mathrm{mg} / \mathrm{L} \mathrm{NaCl})$ lethal challenges were similar, the IED hypothesis would predict very minimal mortality in survivors of the first exposure. This was not the case. This clear deviation from predictions based on the IED concept provided strong support for the stochasticity hypothesis that proneness to die is determined by a stochastic process occurring similarly in all individuals. The argument could be forwarded that the IED concept was correct but a general weakening of the mosquitofish during the first lethal challenge produced the observed high mortality in fish surviving a previous lethal exposure. This general weakening

Table 2. Proportional hazard model for $\mathrm{NaCl}$ time-to-death data

\begin{tabular}{|c|c|c|c|c|c|}
\hline Variable & Label & Estimate & $\begin{array}{c}\text { Standard error } \\
\text { of estimate }\end{array}$ & $\chi^{2}$ & $\begin{array}{c}\text { Probability of } \\
\text { getting } \chi^{2} \text { of this } \\
\text { size by chance alone }\end{array}$ \\
\hline$b_{0}$ & Intercept & 6.231 & 0.088 & $4,967.73$ & 0.0001 \\
\hline \multirow[t]{2}{*}{$b_{1}$} & Lethal pretreatment & 0.101 & 0.081 & 1.58 & 0.2081 \\
\hline & Sublethal pretreatment & 0 & 0 & & \\
\hline$b_{2}$ & ln of wet weight $(\mathrm{g})$ & 0.110 & 0.086 & 1.65 & 0.1986 \\
\hline$\sigma$ & Scale & 0.419 & 0.037 & & \\
\hline
\end{tabular}


Table 3. Accelerated failure time models for pentachlorophenol time-to-death data

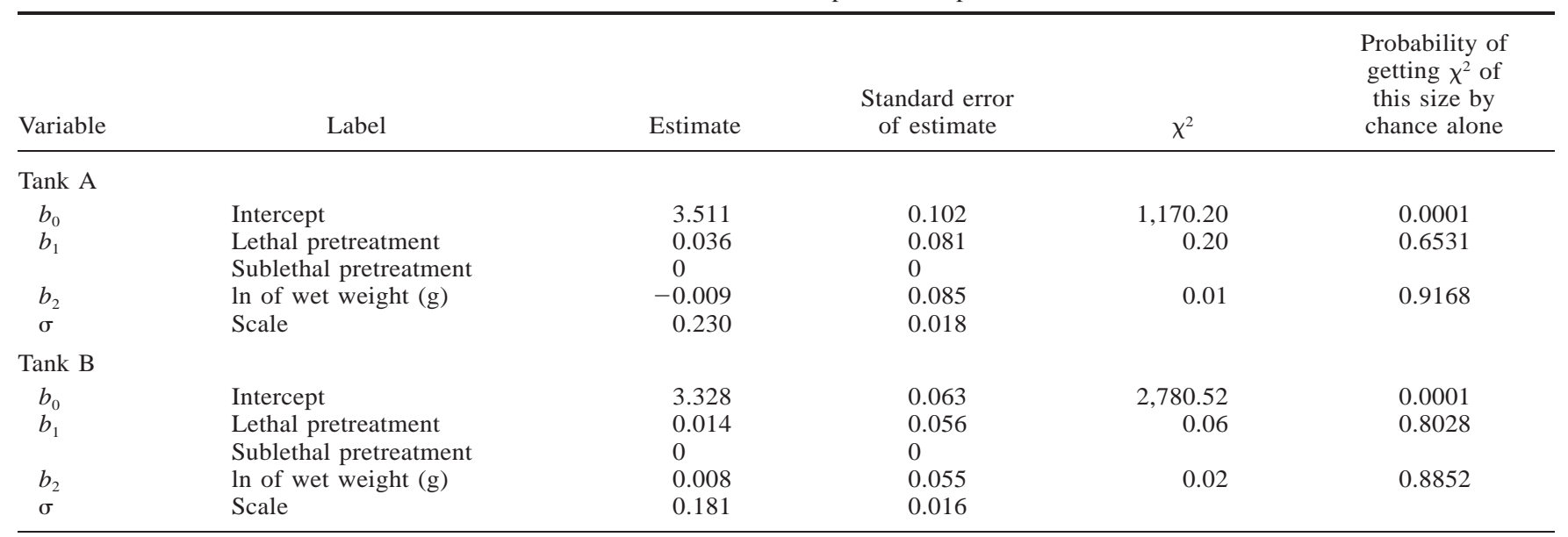

explanation is reinforced by the continual mortality in this treatment weeks after the first lethal exposure. This mortality and the general mechanism of salinity stress suggest damage to these mosquitofish could have been present during the second challenge. However, fish were allowed time to recover from the first exposure and sublethally challenged fish were exposed to high $\mathrm{NaCl}$ concentrations too. The general weakening explanation is also not the most parsimonious explanation because it requires two assumptions (IED hypothesis and the assumption of sustained damage) instead of one (stochasticity hypothesis). As will be discussed for the PCP experiment, such an alternative explanation is not a viable one for similar results from the PCP exposures. Therefore, the most likely explanation for the observed data is the stochasticity hypothesis.

The PCP experiment produced no evidence to support the IED hypothesis. The lack of preexposure treatment (lethal versus sublethal) effect on survival during the final lethal challenge provides clear support for the stochasticity hypothesis. Although some acclimation to PCP occurs after the initial exposure [20], this adaptive change in tolerance provides an inadequate explanation for the observed lack of differences between the mosquitofish of the two treatments. Notice that, relative to the $\mathrm{NaCl}$ experiment, the postexposure mortality for the PCP exposure was relatively minor and ended soon after exposure terminated. Therefore, the general weakening explanation, as discussed above for the $\mathrm{NaCl}$ data, is not a viable alternative explanation for the PCP results.

\section{Conclusion}

The IED hypothesis is rejected as sufficient explanation for the lognormal (probit) model used so often to analyze doseor concentration-effect data. Although clearly supported by the $\mathrm{NaCl}$ and $\mathrm{PCP}$ experimental results, the stochasticity hypothesis also fails as the sole or dominant explanation in all cases. Therefore, the underlying processes giving rise to the distribution of various individual responses (e.g., TTD, TTS, and other metrics) can be an undetermined mixture of the IED and stochastic components described here.

These findings have general significance relative to how environmental consequences of toxicant exposure are translated into predictions of effect during risk assessment. As described in the Introduction, the predicted fates of populations are quite different under the two hypotheses. The IED concept would predict a rapid culling of individuals with low IED values and an epiphenomenal decrease in effect to the surviving population through subsequent exposures. In sharp contrast, the stochasticity hypothesis predicts a gradual decrease in numbers of individuals with a higher probability of local population extinction with repeated exposure. The results indicate that neither hypothesis alone can be assumed true, and that knowledge of the relative contributions of stochasticity and innate qualities of individuals is required to make accurate predictions. Such accurate prediction of population consequences of toxicant exposure is crucial for effective ecological risk assessment. Both our pilot studies for this report and published work with mercury toxicity [21] suggest that any innate differences among individuals may be more manifest at low concentrations and be overshadowed at higher concentrations by predominantly stochastic processes.

Acknowledgement-This research was supported by financial assistance award DE-FC09-96SR18546 from the U.S. Department of Energy to the University of Georgia Research Foundation.

\section{REFERENCES}

1. Bliss CI, Cattell M. 1943. Biological assay. Annu Rev Physiol 5: 479-539.

2. Bliss CI. 1935. The calculation of the dosage-mortality curve. Ann Appl Biol 22:134-307.

3. Finney DJ. 1947. Probit Analysis. A Statistical Treatment of the Sigmoid Response Curve. Cambridge University Press, Cambridge, UK.

4. Gaddum JH. 1953. Bioassays and mathematics. Pharmacol Rev 5:87-134.

5. Berkson J. 1951. Why I prefer logits to probits. Biometrics 7: 327-339.

6. Amdur MO, Doull J, Klaassen CD, eds. Casarett and Doull's Toxicology: The Basic Science of Poisons, 4th ed. Pergamon, New York, NY, USA.

7. Forbes VE, Forbes TL. 1994. Ecotoxicology in Theory and Practice. Chapman \& Hall, London, UK.

8. Suter GW II. 1993. Ecological Risk Assessment. Lewis, Chelsea, MI, USA.

9. Connell DW, Miller GJ. 1984. Chemistry and Ecotoxicology of Pollution. John Wiley \& Sons, New York, NY, USA.

10. Landis WG, Yu M-H. 1995. Introduction to Environmental Toxicology: Impacts of Chemicals upon Ecological Systems. CRC, Boca Raton, FL, USA.

11. SAS Institute. 1989. SAS ${ }^{\circledR} / S T A T$ User's Guide. Version 6, Vol 2. Cary, NC, USA.

12. Newman MC, Aplin M. 1992. Enhancing toxicity data interpretation and prediction of ecological risk with survival time modeling: An illustration using sodium chloride toxicity in mosquitofish (Gambusia holbrooki). Aquatic Toxicol 23:85-96. 
13. Schreck CB, Moyle PB. 1990. Methods for Fish Biology. American Fisheries Society, Bethesda, MD.

14. U.S. Environmental Protection Agency. 1978. Quality assurance guidelines for biological testing. EPA-600/4-78-043. Environmental Monitoring and Support Laboratory, Cincinnati, $\mathrm{OH}$.

15. Newman MC, Keklak MM, Doggett SM. 1994. Quantifying animal size effects on toxicity: A general approach. Aquat Toxicol 28:1-13.

16. Mulvey M, Newman MC, Chazal A, Keklak MM, Heagler HG, Hales S. 1995. Genetic and demographic changes in mosquitofish (Gambusia holbrooki) populations exposed to mercury. Environ Toxicol Chem 14:1411-1418.

17. Tachikawa M, Sawamura R. 1994. The effects of salinity on pen- tachlorophenol accumulation and elimination by killifish (Oryzias latipes). Arch Environ Contam Toxicol 26:304-308.

18. Carr RS, Thomas P, Neff JM. 1982. A simple spectrophotometric technique for the determination of pentachlorophenol in water. Bull Environ Contam Toxicol 28:477-479.

19. SAS Institute. 1996. Advanced General Linear Models with an Emphasis on Mixed Models. Cary, NC, USA.

20. Norup B. 1972. Toxicity of chemicals in paper factory effluents. Water Res 6:1585-1588

21. Heagler MG, Newman MC, Mulvey M, Dixon PM. 1993. Allozyme genotype in mosquitofish, Gambusia holbrooki, during mercury exposure: Temporal stability, concentration effects and field verification. Environ Toxicol Chem 12:385-395.

\section{ERRATA}

Dodson SI, Merritt CM, Shannahan J-P, Shults CM. 1999. Low exposure concentrations of atrazine increase male production in Daphnia pulicaria. Environ Toxicol Chem 18:1568-1573.

The 95\% confidence intervals shown in Figure 3 were calculated incorrectly. The intervals were calculated using $n$ (sample size) instead of $n-1$ for degrees of freedom used to select the t value. This means the intervals are smaller than they should be. The standard errors of the mean (SEM in Table 1) were calculated incorrectly for atrazine concentrations of 50, 100, 250, and 500 ppb. When the correct number of degrees of freedom and the correct standard error values are used, the data show that atrazine exposure concentrations from $500 \mathrm{ppb}$ down to $5 \mathrm{ppb}$ significantly increased male production in Daphnia, but that effects associated with concentrations of $1.0 \mathrm{ppb}$ to $0.01 \mathrm{ppb}$ were not significantly different from zero. We thank representatives of Novartis Crop Protection AG (makers of atrazine) for drawing this issue to our attention.

Lussier SM, Kuhn A, Comeleo R. 1999. An evaluation of the seven-day toxicity test with Americamysis bahia (formerly Mysidopsis bahia). Environ Toxicol Chem 18:2888-2893.

Line 16 of the first paragraph of the section titled "'Experimental design," page 2889 the parenthetical expression, “(30-ml plastic cups)" should read "(200-ml plastic cups)." 